\title{
Projetos locais de desenvolvimento no contexto das cadeias de suprimentos de montadoras de motores veteranas e entrantes
}

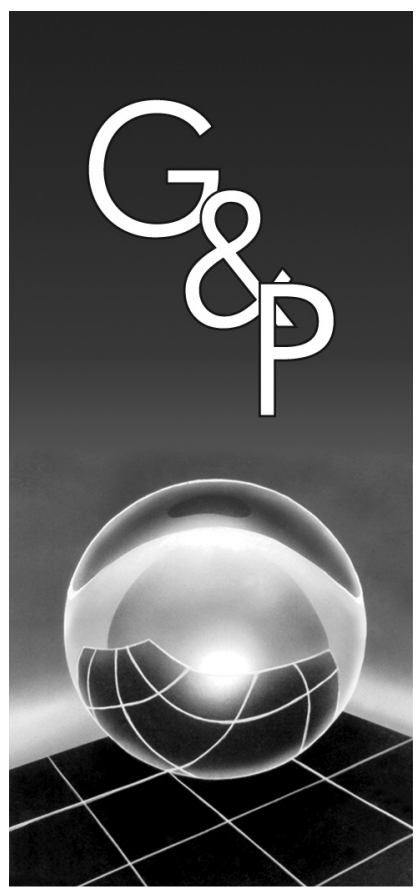

\author{
Aline Lamon Cerra \\ Jonas Lucio Maia \\ Alceu Gomes Alves Filho
}

Resumo

O objetivo do trabalho é identificar e comparar as atividades de projetos de desenvolvimento (produto e processo) realizadas por duas montadoras veteranas e uma entrante, considerando o contexto das cadeias de suprimentos nas quais estão inseridas. Para isso, foram realizados estudos de caso em três montadoras de motores e em oito fornecedores. A maior parte das empresas estudadas responsabiliza-se pelas atividades relacionadas ao projeto dos processos de produção. No caso das montadoras veteranas, isto ocorre praticamente sem auxílio externo (com apoio apenas eventual de suas matrizes), possivelmente pelo fato da tecnologia de produção estar consolidada, sofrendo apenas mudanças incrementais, $e$ das competências necessárias já terem sido localmente desenvolvidas. No caso da montadora entrante, como seus processos de produção foram há pouco instalados, a subsidiária no Brasil tem se responsabilizado pelas poucas mudanças desde então implementadas. Nos fornecedores estudados, as alterações nos processos não são também de grande monta e eles podem contar, em certos casos, com o auxílio das montadoras. O projeto de produtos recebe grande atenção por parte das montadoras. As montadoras veteranas estudadas já fizeram desenvolvimentos locais relevantes e a entrante planeja ampliar seu setor de desenvolvimento de produtos, visando à possibilidade de iniciar desenvolvimentos locais e, principalmente, nacionalizar sua base de fornecedores. No que diz respeito aos fornecedores, os resultados desta pesquisa indicam que os níveis exigidos de capacidade tecnológica em desenvolvimento de produto podem variar segundo os segmentos tecnológicos das cadeias de suprimentos na indústria automobilística. No segmento dos componentes metálicos, os fornecedores ou recebem das montadoras os projetos de produtos completamente especificados ou desenvolvem projetos a partir das exigências colocadas pelas montadoras. No segmento dos eletrônicos, os fornecedores dominam a tecnologia e desenvolvem componentes que as montadoras apenas "aplicam" em seus produtos. Já os fornecedores de componentes poliméricos parecem ocupar nível intermediário de domínio tecnológico de produtos entre os segmentos de componentes metálicos e eletrônicos.

Palavras-chave: Projetos de desenvolvimento (produtos e processos). Motores automotivos. Cadeias de suprimentos. Indústria automobilística.

\section{Introdução}

A partir da década de 90 , pode-se verificar a ocorrência de diversas mudanças ao longo das cadeias automotivas mundiais, alterações estas que produziram um conjunto de impactos nas relações entre firmas. Dentre elas, tem-se que as grandes montadoras puderam se concentrar em questões mais especializadas em nível de produto, priorizando atividades e competências relativas à criação de características que identificarão o produto junto ao mercado consumidor, cabendo aos seus fornecedores diretos a responsabilidade sobre o aprimoramento tecno- lógico dos diferentes sistemas que irão compor o veículo (PEREIRA; GEIGER, 2005). Esses fornecedores, por sua vez, repassaram parte de suas atividades para os fornecedores atuantes em níveis inferiores da cadeia de suprimentos, os quais se especializaram na produção de parte desses sistemas.

A indústria automobilística brasileira, no período em questão, presenciou a instalação de unidades produtivas de diversas montadoras em regiões sem tradição no setor. As montadoras que iniciaram suas atividades produtivas 
no início da indústria automobilística nacional, apresentando investimentos em Pesquisa \& Desenvolvimento (P\&D) e Desenvolvimento de Produtos (DP) menos centralizados no exterior, VW, GM, Fiat e Ford, são denominadas "veteranas" por Consoni (2004) ou "estabelecidas" por Alves Filho et al. (2006). E as montadoras que aqui se instalaram após os anos 90 e apresentam extrema centralização das atividades de engenharia no exterior, sobretudo em relação aos projetos de desenvolvimento de produtos, são denominadas "entrantes" pelos mesmos autores.

No que tange aos Projetos de Desenvolvimento de Produtos e Processos (PDPPs), estudos empíricos têm mostrado que:

a) os PDPPs apresentam diferenças significativas entre as montadoras entrantes e as previamente instaladas no Brasil (CONSONI, 2004; SALERNO et al., 2001); e

b) a instalação destas novas empresas alterou estruturalmente as cadeias no contexto das quais os PDPPs ocorrem (SALERNO et al., 2001).

Neste contexto, Salerno et al. (2001) realizaram uma pesquisa empírica junto às montadoras veteranas de automóveis "sedes de projetos", ou seja, unidades que centralizam a gestão e as decisões sobre os projetos dos veículos, seus desenvolvimentos e suas modificações. Uma das conclusões deste estudo foi que essas subsidiárias ocupavam, até então, uma faixa intermediária entre o projeto/desenvolvimento autônomo integral de um veículo e a adaptação simples e sem maiores mudanças de um projeto já definido. Os dados da pesquisa destes autores (quantitativos e qualitativos) foram obtidos durante o ano de 2001 e mostraram que as montadoras que aqui sediam e desenvolvem atividades de desenvolvimento de produtos adotam a estratégia de atuar com veículos específicos para as características de mercados de um grupo considerado homogêneo de "países emergentes” (América Latina, África, Oriente Médio, China), desenvolvendo produtos de nicho que possam atingir volumes razoáveis. Já as montadoras entrantes, radicadas no Brasil a partir de meados da década de 90, não apresentam atividades significativas de projeto de produto.

Entretanto, pesquisas precisariam ser realizadas para investigar as atividades de desenvolvimento de produtos dessas montadoras de automóveis nos anos atuais, já que modelos de sucesso de mercado foram mais recentemente desenvolvidos pelas montadoras de veículos locais, como, por exemplo, o EcoSport da Ford, Celta, Meriva e Novo Vectra da GM, Palio (parcialmente desenvolvido no Brasil) e o Fox da Volkswagen (QUINTELLA; ROCHA, 2006), alguns não voltados apenas aos países emergentes.

O automóvel é um importante vetor de inovação e de difusão de novas tecnologias (MEDINA, 2000 apud
ALVAREZ, 2004). Os autoveículos são produtos de elevada complexidade técnica, que tende a aumentar à medida que novas tecnologias são incorporadas e os ciclos-de-vida dos produtos são reduzidos (ALVAREZ, 2004).

Segundo Alves Filho et al. (2007), no grupo das estabelecidas, as empresas montadoras de veículos adotam estratégias competitivas semelhantes, participando mais ou menos da mesma forma nos diversos segmentos de mercado da indústria automobilística e atribuindo a suas fábricas de motores papéis também similares.

O segmento de produção de motores é da mesma forma relevante. Estima-se que o motor seja responsável por aproximadamente $20 \%$ dos custos de produção de um veículo completo, número que pode ser considerado alto quando se analisa a diversidade de componentes e autopeças existentes em um automóvel inteiro (Maia, 2006). Além disso, a relevância estratégica dos motores também deve ser analisada sob o prisma do próprio Desenvolvimento de Produtos, considerando que o Brasil presenciou, nos últimos anos, fenômenos como a introdução dos motores de 1000 cilindradas, dos motores "flexíveis" capazes de operar com qualquer mistura dos combustíveis álcool e gasolina, e a constituição de jointventures para a produção conjunta de motores (como a FIAT-GM- Powertrain, desfeita no primeiro semestre de 2005) (MAIA; CERRA, 2005).

Embora as subsidiárias brasileiras tenham desenvolvido projetos relevantes como os mencionados acima, na maior parte dos casos os Projetos de Desenvolvimento de Produtos de Processos (PDPPs) se concentram em adaptações e melhorias de produtos e processos existentes às condições do mercado local, à estrutura de fornecedores existentes e aos processos de produção disponíveis. Segundo Rozenfeld et al. (2006), é importante ressaltar que, mesmo que a tecnologia e a concepção de um novo produto venham do exterior, existem muitas atividades de desenvolvimento (projeto detalhado, projeto do processo, testes, projeto de fábrica, etc.) que estão inseridas no escopo de desenvolvimento de produtos e que fazem parte das responsabilidades de empresas locais.

Em síntese, as atividades de engenharia no Brasil, base para os PDPPs locais, vêm mudando quanto à qualidade, complexidade e responsabilidade; há certa competência e experiência acumuladas em desenvolvimento de novos produtos (MIGUEL; ROTONDARO, 2006), mas ainda as matrizes são fontes importantes de conhecimentos e tecnologias e concentram as atividades de Pesquisa \& Desenvolvimento.

Neste contexto, e considerando que são raros os estudos que focalizam o segmento de motores para automóveis, as questões centrais desta pesquisa são: quais atividades de projeto (produto e processo) são realizadas pelas montadoras de motores (veteranas e pelas 
entrantes); e que atividades de projeto são distribuídas ao longo das cadeias de suprimentos dessas montadoras e de que forma.

Assim, o objetivo do trabalho é identificar e comparar as atividades de projeto (produto e processo) realizadas por duas montadoras veteranas e uma entrante, considerando o papel de suas cadeias de suprimentos e a relação entre a subsidiária brasileira e a matriz internacional. Para isso serão estudados, além das três montadoras de motores, oito fornecedores de diferentes segmentos, distribuídos entre o primeiro e o segundo nível das mencionadas cadeias.

$\mathrm{O}$ artigo se encontra estruturado da seguinte forma: inicialmente é realizada a revisão da literatura a respeito das atividades de PDPPs realizadas nas subsidiárias automobilísticas instaladas no Brasil; a seguir, o método de pesquisa é apresentado, seguido pela descrição e análise dos estudos de caso; e, ao final, são esboçadas as conclusões e considerações finais, bem como são indicadas as limitações deste estudo e possibilidades de pesquisas futuras.

\section{Projetos de desenvolvimento de produtos e processos na indústria automobilística}

Nesta seção, são abordados temas relacionados aos Projetos de Desenvolvimento de Produtos e Processos (PDPPs) no contexto da indústria automobilística. Assim, são tratados: i) a questão da descentralização das atividades de PDPPs por parte das matrizes e as razões que as levaram a optarem por ela; ii) sob o ponto de vista das subsidiárias que aqui se instalaram, a independência que elas adquiriram em relação às suas respectivas matrizes estrangeiras para desenvolverem atividades de projeto, ou seja, a autonomia tecnológica; iii) os segmentos de automóveis e de montadoras de motores, sendo este último foco deste estudo; e iv) o envolvimento de fornecedores em atividades de PDPPs de montadoras.

As atividades gerenciais do Projeto de Desenvolvimento de Produtos e Processos se desenvolvem com base nos conhecimentos científico e tecnológico oriundos da Pesquisa e Desenvolvimento (P\&D). Conceitualmente, consideramos que os PDPPs "consistem em um conjunto de atividades por meio das quais se busca, a partir das necessidades do mercado e das possibilidades e restrições tecnológicas, e considerando as estratégias competitivas e de produto da empresa, chegar às especificações de projeto de um produto e de seu processo de produção, para que a manufatura seja capaz de produzi-lo" (ROZENFELD et al., 2006).

No que se refere à localização das atividades de PDPPs das empresas automobilísticas que operam no Mercosul, as principais tendências são muito influenciadas pelas distintas estratégias de globalização adotadas pelas montadoras (QUADROS et al., 2000). Segundo os resultados da pesquisa realizada por estes autores, a GM e a Fiat adotaram um enfoque multirregional de globalização, com maior autonomia concedida a suas divisões regionais ou subsidiária local, e aumentaram suas atividades tecnológicas, especialmente relacionadas com o Desenvolvimento de Produtos, assim como ampliaram seus staffs de engenheiros nos anos recentes. A Ford, que havia adotado uma estratégia transnacional de globalização e diminuído o tamanho e a qualificação média de sua área de PDPPs, iniciou um processo de reversão deste quadro ao instalar o Complexo Industrial no município de Camaçari em 2001.

A Volkswagen, no início de suas operações no Brasil, optou por realizar localmente certas atividades de desenvolvimento de produtos: a princípio eram essencialmente adaptações de produtos, e ao longo do tempo resultaram em competências técnicas e gerenciais para projetos. Tais atividades diminuíram após a abertura do mercado, porém foram retomadas no início dos anos 2000 (DIAS; SALERNO, 2003).

Durante este mesmo período, conforme já mencionado, novas montadoras adentraram no cenário automotivo brasileiro (Renault, PSA Peugeot Citroën, Toyota, Honda e Daimler Chrysler), centralizando em suas matrizes estrangeiras as atividades de engenharia, sobretudo as de PDPPs (CONSONI, 2004).

A pesquisa empírica de Dias e Salerno (2003) indica que as razões que levam uma firma transnacional a descentralizar o desenvolvimento de seus produtos globais vão além dos motivos comumente alegados na literatura, tais como a necessidade de estar próximo ao mercado e o acesso à tecnologia local. Para os autores, a decisão sobre centralizar ou não o desenvolvimento de produtos globais relaciona-se a opções estratégicas que visam aumentar a competitividade da empresa. Desse modo, a busca pela redução do tempo de desenvolvimento também é um fator que explica a opção pela descentralização, quando os produtos destinados aos mercados das subsidiárias sofrem muitas adaptações com relação aos produzidos pelos centros de projeto e quando o tempo for dimensão competitiva importante para a empresa.

Diretamente relacionada à questão da descentralização dos Projetos de Desenvolvimento de Produtos e Processos, tem-se a avaliação do grau de autonomia concedido pelas matrizes internacionais a suas subsidiárias locais para a realização destas atividades.

$\mathrm{O}$ acúmulo de capacidades e recursos em uma subsidiária depende, dentre outros fatores, de desenvolvimento criativo e de novas combinações de conhecimentos (GOMES, 2003). Esta combinação de conhecimentos é base para que as organizações possam assimilar e explorar um novo conhecimento, de modo que o acúmulo de 
recursos depende também da "capacidade de absorção" (absorptive capability) (COHEN; LEVINTHAL (1990).

No início da indústria automobilística brasileira, as subsidiárias mantinham-se totalmente dependentes das suas empresas matrizes quanto ao desenvolvimento de produtos tecnologicamente mais sofisticados e à introdução de processos de produção mais inovadores, quando houve uma tentativa de padronização do design.

Com o passar do tempo, adaptações locais foram necessárias, dadas as preferências dos consumidores locais, as diferentes condições das estradas, as características de materiais locais, especificações e custos em relação a regras locais em segurança e poluição (HUMPHREY; SALERNO, 2000). Nesta fase, as capacidades tecnológicas acumuladas nos países em desenvolvimento se referiam a esforços localizados de adaptação dos produtos e dos processos de manufatura às condições locais de mercados e insumos, e que se sustentavam a partir da incorporação de tecnologias geradas no exterior (CONSONI, 2004).

No entanto, segundo Humphrey e Salerno (2000), novos investimentos em mercados emergentes tornaram-se estratégicos não apenas para montadoras, mas também para os fornecedores dos primeiros níveis e subsidiárias de companhias transnacionais. Conseqüentemente, as indústrias automobilísticas destes países foram sendo estruturalmente transformadas, e muitas atividades de desenvolvimento passaram a ser realizadas.

Exemplo de desenvolvimento local de destaque no âmbito das montadoras de automóveis é o Projeto Meriva da GM do Brasil, que representou evolução em relação à plataforma que dá origem ao modelo e envolveu alterações na própria arquitetura do veículo. Segundo Consoni (2004), este projeto ajudou a disseminar uma visão positiva acerca do potencial técnico da engenharia brasileira e da capacidade local em propor soluções de baixo custo nos PDPPs. Cabe mencionar ainda os exemplos do EcoSport e do Ford Ka, dentre outros.

No que diz respeito ao desenvolvimento e produção de motores, tem-se como desenvolvimentos locais os motores de baixas cilindradas, motores a álcool e os motores com sistemas bicombustíveis. Vale ressaltar que alguns desses modelos são exportados, como, por exemplo, o motor 1.4 do Volkswagen Fox que é utilizado na Europa.

No Brasil, diferentemente do que ocorreu nos Estados Unidos (onde os sistemas foram originalmente lançados), os estudos para a aplicação da tecnologia dos motores bicombustíveis ("flexíveis") se iniciaram em empresas de autopeças do segmento eletrônico, especificamente na Bosch, em 1991.

O motor bicombustível funciona de maneira similar a um motor convencional, que serviu de base para o desenvolvimento do sistema Flex Fuel. Embora existam algumas alterações mecânicas no motor, como o tratamento das peças e alterações na taxa de compressão, as principais mudanças ocorrem no sistema eletrônico que gerencia o seu funcionamento (CERRA, 2005). A partir do monitoramento do sensor chamado "sonda lambda", a central eletrônica ECM (do inglês, engine control module) identifica a proporção da mistura álcool-gasolina e ajusta o funcionamento do motor, alterando o ponto de ignição, o tempo de injeção de combustível e a abertura e o fechamento das válvulas (TEIXEIRA, 2005).

Em 1994, essa tecnologia estava pronta para ser comercializada, mas na época não houve interesse por parte do governo (que mantinha a tributação para estes motores similar àquela dos motores a gasolina) nem por parte das montadoras (que não viam vantagem em investir nesse novo sistema, por não terem nenhum incentivo adicional). Em 1999 a Magneti Marelli anunciou também dispor dessa tecnologia. Em 2002 foi definido que veículos com sistema flex fuel seriam tributados como carros a álcool, em que a alíquota de incidência de impostos (ex. IPI - Imposto sobre Produtos Industrializados) é menor (TEIXEIRA, 2005).

A produção de carros equipados com motores de combustíveis flexíveis no Brasil é crescente. Quando lançado no ano de 2003, este modelo correspondia a 2,6\% da produção total de motores e, em 2006, esse percentual já totalizava 59,7\% (ANFAVEA, 2007).

Por outro lado, os chamados "carros populares" de $1000 \mathrm{cc}$, que respondiam pela maior parcela do crescimento de vendas, a partir de 2005 apresentaram queda de volume de produção em relação aos "não-populares". Estes últimos, segundo dados da FENABRAVE, ficaram em 2005 com 54,6\% da produção total.

A partir de 1997 a Magneti Marelli brasileira começou a desenvolver o sistema denominado Tetra Fuel, software totalmente desenvolvido no Brasil que permite que o motor seja abastecido com álcool, gasolina, nafta (gasolina pura) e gás natural. O primeiro carro nacional a ser equipado com esta tecnologia foi o Siena da Fiat, lançado em 2006 nesta versão e produzido pela planta da empresa em Betim-MG.

Sendo os motores considerados estratégicos para a competitividade do setor, e dado que:

a) estes possuem componentes importantes desenvolvidos por fornecedores, como é o exemplo dos motores de combustíveis flexíveis, e

b) é grande a quantidade de componentes terceirizados pelas montadoras, pode-se dizer que, no segmento de motores, a tendência das montadoras transferirem mais competências a fornecedores especializados de fato vem ocorrendo.

Nas cadeias de suprimentos do segmento de motores brasileiro, diferentemente do que ocorre com as montadoras de automóveis aqui instaladas, não foram 
implantados arranjos como o Consórcio Modular ou Condomínio Industrial. As iniciativas quanto ao fornecimento de subconjuntos de maior valor agregado ainda são incipientes e as montadoras de motores têm implementado modelos distintos quanto ao número de fornecedores por componente ou peça adquirida. Estas montadoras de motores apresentam também diferenças relevantes entre si quanto ao mix e escala de produção, no nível de outsourcing dos componentes, as configurações das cadeias (refletidas no número e localização dos fornecedores) além do grau de cooperação entre montadoras e fornecedores (ALVES FILHO et al., 2006; MAIA, 2006; CERRA, 2005).

Uma vez sintetizadas as questões de descentralização de atividades e autonomia local, bem como alguns estudos empíricos sobre o tema, procedemos a outro aspecto de interesse neste trabalho: o envolvimento de fornecedores automotivos nos PDPPs das montadoras.

Projetos bem sucedidos de Desenvolvimento de Produtos e Processos possuem caráter essencialmente interdisciplinar, requerendo inputs oriundos das diversas áreas da organização e dependendo de uma variedade de fatores que incluem (SILVA; FERREIRA, 2006):

a) a natureza e a qualidade da informação sobre as características do mercado;

b) elevado conhecimento das atividades de produção;

c) a compatibilidade dos recursos com as exigências do projeto do produto novo;

d) o nível e a complexidade da tecnologia utilizada; e

e) o nível desejado de inovação.

Segundo Fernandes et al. (2005), quando um novo produto envolve altos níveis de inovação tecnológica, surge uma lacuna entre o montante de conhecimento necessário para a realização de tal desenvolvimento e o montante de conhecimento já processado na organização. Nestes casos, existem experiências acumuladas em atividades de projetos anteriores que poderão ser tomadas como base para o novo projeto em questão; assim, faz-se necessário que haja fácil acesso às informações e maior integração dentro da organização.

As questões de gestão de conhecimento e informações assumem caráter ainda mais complexo e relevante quando se considera a distribuição do conhecimento para projetos de desenvolvimento ao longo das diversas empresas que compõem as cadeias automobilísticas. Neste sentido, novas formas de coordenação organizacional e de informação têm sido implantadas na indústria automobilística global, visando, dentre outras coisas, estimular a cooperação de fornecedores desde estágios iniciais das atividades de PDPPs, melhorar a velocidade e eficiência do processo, reduzir estoques e realizar entregas just-intime nas atividades de montagem (VOLPATO, 2003).

Além do aumento da troca de informações, segundo Silva, et al. (2005), vários estudos (CLARK; FUJIMOTO,
1991; WOMACK et al. 1990; BROWN; EISENHARDT, 1995; KESSELER, 1997 apud SILVA, et al., 2005) apontam para a importância de envolver fornecedores nos Projetos de Desenvolvimento de Produtos e Processos, enfatizando a transferência de responsabilidade das inovações e produção de componentes e sistemas para os fornecedores e liberando a empresa para se concentrar em seu core business de projeto e montagem de automóveis (TOLEDO et al., 2005).

A questão do envolvimento e responsabilidade de fornecedores é, segundo Quiescenti et al. (2006), fator determinante do desempenho em desenvolvimento de novos produtos. Quanto mais cedo no processo de desenvolvimento do produto for estabelecida a integração entre clientes e fornecedores no projeto de novos produtos, mais efetiva será a redução de custos e de tempo de desenvolvimento (RAGATAZ et al., 1997 apud ASSUMPÇÃO, 2003). É nas fases iniciais que as decisões críticas são tomadas, não apenas quanto à funcionalidade do produto para o consumidor, mas também a fonte de materiais, assim como a seleção dos processos tecnológicos.

No entanto, há ainda outros aspectos a serem considerados no envolvimento de fornecedores em DP - os riscos potenciais e problemas que podem ocorrer como a perda da propriedade de conhecimento (LAKEMOND et al., 2006), redução de controle sobre o processo de desenvolvimento e o custo do gerenciamento da colaboração (MIKKOLA; SKJOETT-LARSEN, 2003). Outros riscos inerentes a este processo podem ser: desvalorizar competências internas; facilitar acesso aos competidores para copiar e/ou adquirir tecnologias-chave; aumentar a dependência de fornecedores estratégicos; e aumentar a padronização de componentes devido às interfaces especificadas.

Além dos riscos envolvidos, deve-se considerar que nem sempre os fornecedores podem estar suficientemente capacitados para os desenvolvimentos. De acordo com Mikkola e Skjoett-Larsen (2003), se um dado fornecedor não possui as capacidades técnicas necessárias, o cliente pode ter que auxiliá-lo a desenvolvê-las ou optar por sua substituição. A questão do auxílio, tratada neste artigo como "desenvolvimento de fornecedores", pode abranger desde esforços limitados, como avaliar o fornecedor e exigir aumento de desempenho, quanto esforços extensivos, como, por exemplo, treinamento do pessoal do quadro funcional do fornecedor e investimentos em suas operações (NEUMANN; RIBEIRO, 2004). Segundo Neumann e Ribeiro, é essencial que a empresa dê continuidade às ações iniciadas junto aos fornecedores, permitindo que as ações empreendidas durante o programa sejam incorporadas como práticas comuns e rotineiras.

A presente seção buscou realizar uma síntese da literatura acerca das atividades de projeto na indús- 
tria automotiva que servirá de base para a condução da pesquisa empírica a seguir descrita.

\section{Método}

O trabalho se estrutura basicamente em duas partes: revisão bibliográfica acerca dos tópicos associados ao tema e pesquisa de campo.

A pesquisa de campo foi realizada por meio de estudos de caso e, portanto, pode ser caracterizada como qualitativa e descritiva (ou exploratória). A pesquisa descritiva ou exploratória, de acordo com Cervo e Bervian (1983), designa situações em que a pesquisa é realizada por meio de observações, registros, análise e correlações de dados em situações em que há pouco conhecimento sobre o assunto estudado.

Foram então realizados estudos de caso nas três montadoras escolhidas e em oito fornecedores, fundamentados em entrevistas semi-estruturadas que duraram cerca de uma hora cada. Estas empresas foram selecionadas de acordo com trabalhos anteriores do grupo de pesquisa junto ao setor automotivo, julgando que estas são as que trariam mais elementos para a discussão do tema proposto neste trabalho. Assim, optou-se por contemplar tanto montadoras "veteranas" quanto "entrantes", e fornecedores dos segmentos metal-mecânico, eletrônico e polimérico, com predominância do primeiro (assim como ocorre na realidade das cadeias).

Nas empresas, as pessoas entrevistadas foram preferencialmente aquelas ligadas à tecnologia de produtos, processos e gestão, ou seja, diretores ligados à área tecnológica, diretores industriais e gerentes de compras. O número de entrevistas variou conforme a empresa, mas em média foram realizadas duas entrevistas por empresa.

A observação direta, realizada a partir de visitas às empresas, e a pesquisa em dados secundários como páginas das empresas na internet, constituíram importantes origens de informações complementares. Somaram-se, ainda, dados e conhecimentos acumulados em pesquisas anteriores realizadas junto ao segmento de motores para automóveis.

O roteiro de coleta de dados acerca dos PDPPs, além de dados gerais sobre as companhias, buscava identificar quatro questões:

a) atividades de pesquisa e desenvolvimento, que dão o embasamento científico e tecnológico para os projetos;

b) descentralização e autonomia das empresas frente a suas matrizes internacionais;

c) capacitação de suas áreas de projeto; e

d) contexto de mudanças técnicas nos projetos de produto e processo.
Dentro de cada uma destas áreas, as questões mais específicas compõem as primeiras colunas das tabelas apresentadas mais adiante.

\section{Estudos de caso}

De modo a não identificar as empresas, as montadoras serão referenciadas respectivamente como A, B (ambas veteranas) e $\mathrm{C}$ (entrante), e os fornecedores numerados de 1 a 8. A Figura 1 identifica as relações entre as diversas empresas da amostra.

No primeiro nível de suprimentos, têm-se cinco fornecedores. Dois deles pertencem à cadeia da Montadora $\mathrm{A}$, embora forneçam componentes a outras montadoras não presentes nesta amostra. Do mesmo modo, outros dois fornecedores estão posicionados na cadeia da Montadora B. Há ainda um fornecedor que pertence a ambas e, por isso, encontra-se situado sobre a linha que delimita as cadeias A e B. Outros dois fornecedores, as empresas 2 e 3, além de fornecerem diretamente às montadoras (primeiro nível), fornecem componentes também para empresas de autopeças fornecedoras das montadoras (segundo nível). Por fim, o Fornecedor 8 pertence exclusivamente ao segundo nível.

De forma a permitir a análise comparativa entre as empresas, optou-se aqui por apresentar os dados de forma tabular e não em texto corrente. As Tabelas 1 e 3 sintetizam as características gerais das montadoras e dos fornecedores, respectivamente. As Tabelas 2 e 4 sintetizam diversas características relativas aos projetos de desenvolvimento de produtos e processos que desenvolvem.

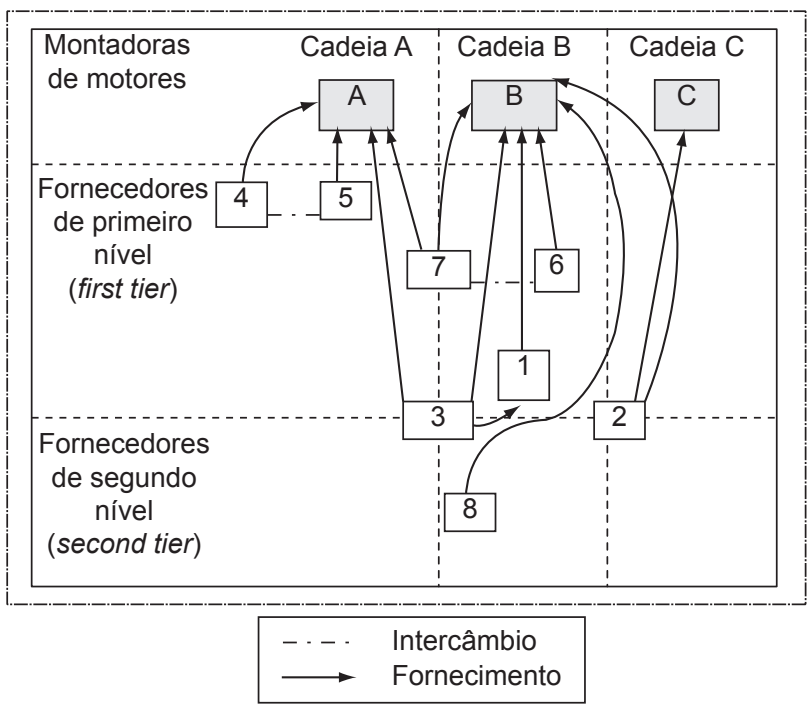

Figura 1. Relações de fornecimento entre as empresas das cadeias de suprimentos. 
Tabela 1. Características gerais das montadoras de motores.

\begin{tabular}{|c|c|c|c|}
\hline & \multicolumn{2}{|c|}{ Veteranas } & \multirow{2}{*}{$\frac{\text { Entrante }}{\text { Montadora C }}$} \\
\hline & Montadora A & Montadora B & \\
\hline $\begin{array}{c}\text { Linhas de produtos } \\
\text { (motores) }\end{array}$ & $\begin{array}{l}\text { Motores } 1.0,1.4 \text { e } 1.6 \text {. } \\
\text { Compreende } 31 \text { modelos de } \\
\text { motores. }\end{array}$ & $\begin{array}{l}\text { Motores } 1.0,1.4,1.6 \text { e } 1.8 \\
\text { Motores } 1.8,2.0,2.2 \text { e } 2.4\end{array}$ & $\begin{array}{l}\text { Motores } 1.4 \text { e } 1.6 \text {. } \\
\text { Compreende } 23 \text { modelos de } \\
\text { motores. }\end{array}$ \\
\hline $\begin{array}{c}\text { Capacidade instalada de } \\
\text { produção }\end{array}$ & 1800 motores/dia & $\begin{array}{l}1650 \text { motores/dia } \\
700 \text { motores/dia }\end{array}$ & 1000 motores/dia \\
\hline Produção efetiva & 1650 motores/dia & $\begin{array}{l}1650 \text { motores/dia } \\
300 \text { motores/dia }\end{array}$ & 520 motores/dia \\
\hline $\begin{array}{c}\text { Componentes produzidos } \\
\text { internamente e componentes } \\
\text { terceirizados }\end{array}$ & $\begin{array}{l}\text { Faz internamente a usinagem } \\
\text { do bloco. Pretende, a partir } \\
\text { de } 2007 \text {, usinar e montar os } \\
\text { cabeçotes. } \\
\text { Terceiriza a fundição e os } \\
\text { demais componentes. }\end{array}$ & $\begin{array}{l}\text { Faz internamente a fundição de } \\
\text { parte dos componentes. } \\
\text { Pretende terceirizar a fundição. } \\
\text { Terceiriza a usinagem e os } \\
\text { demais componentes. }\end{array}$ & $\begin{array}{l}\text { Faz internamente: a usinagem } \\
\text { do bloco, virabrequim, biela e } \\
\text { cabeçote. } \\
\text { Terceiriza a fundição e os } \\
\text { demais componentes. }\end{array}$ \\
\hline Fornecedores & $\begin{array}{l}\text { Cerca de } 210 \text {. } \\
\text { Maior parte empresas nacionais } \\
\text { de pequeno e médio portes. }\end{array}$ & $\begin{array}{l}\text { Aproximadamente } 100 . \\
\text { Maior parte empresas } \\
\text { multinacionais. }\end{array}$ & $\begin{array}{l}92 \text { (32 localizados no Brasil e } \\
\text { os demais no exterior) - } \\
\text { empresas multinacionais. }\end{array}$ \\
\hline
\end{tabular}

Tabela 2. Características dos PDPPs das montadoras.

\begin{tabular}{clcc}
\hline & \multicolumn{1}{c}{ Veteranas } & \multicolumn{1}{c}{ Entrante } \\
\cline { 2 - 3 } Pesquisa e Desenvolvimento \\
(P\&D) & \multicolumn{1}{c}{ Montadora A } & Montadora B centro de pesquisa local, Idem Montadora A. & Todas as atividades de P \& D, \\
& $\begin{array}{l}\text { mas as atividades de pesquisa } \\
\text { tecnológica estão concentradas } \\
\text { na matriz estrangeira. }\end{array}$ & $\begin{array}{l}\text { além de desenvolvimento de } \\
\text { produtos, estão concentradas na } \\
\text { matriz estrangeira. }\end{array}$
\end{tabular}

Produtos que destacam a subsidiária em relação à matriz

Estrutura do setor da engenharia de produtos motores

Mudanças tecnológicas em produtos/motores

Mudanças tecnológicas em processos de produção

Design de componentes terceirizados
Motores de baixas cilindradas; Idem Montadora A.

motores a álcool;

motores com sistema de com-

bustível flexível.

180 pessoas fora os projetistas 200 pessoas fora os projetistas temporários.

temporários

Todos os engenheiros, 108 com 80 engenheiros, 20 com póspós-graduação.

graduação.

Os modelos de motores desen- Idem Montadora A.

volvidos no Brasil têm como ponto de partida um motor existente.

Trata-se, na maior parte dos ca- Idem Montadora A.

sos, de pequenas adaptações.

Podem ocorrer durante a fase de

projeto e nas linhas de produção

já em operação.

Podem ser verificadas três situa- Podem ser verificadas duas ções distintas: situações distintas:

$\mathrm{O}$ fornecedor desenvolve e fabri- $\mathrm{O}$ fornecedor desenvolve e ca o componente;

fabrica o componente; e

A montadora cede o projeto do A montadora cede o projeto do produto e o fornecedor desenvol- produto e o fornecedor desenve o processo e o fabrica; e volve o processo e o fabrica.

A montadora cede o projeto do Situação incomum: produto e do processo e auxilia o A montadora cede o projeto do fornecedor na fabricação. produto e do processo e auxilia o fornecedor na fabricação.
Na subsidiária ainda não são desenvolvidos produtos. Destacase por apresentar menores índices de problemas de qualidade em processos de produção.

7 pessoas.

Todos são engenheiros e alguns com pós-graduação.

As atividades de DP estão se iniciando. Os motores a serem desenvolvidos terão como ponto de partida um motor existente.

Trata-se, na maior parte dos casos, de pequenas adaptações/ melhorias.

Os processos são pouco flexíveis.

Podem ser verificadas duas situações distintas:

$\mathrm{O}$ fornecedor desenvolve $\mathrm{e}$ fabrica o componente; e

A montadora cede (repassa) o projeto do produto e o fornecedor desenvolve o processo e o fabrica. 


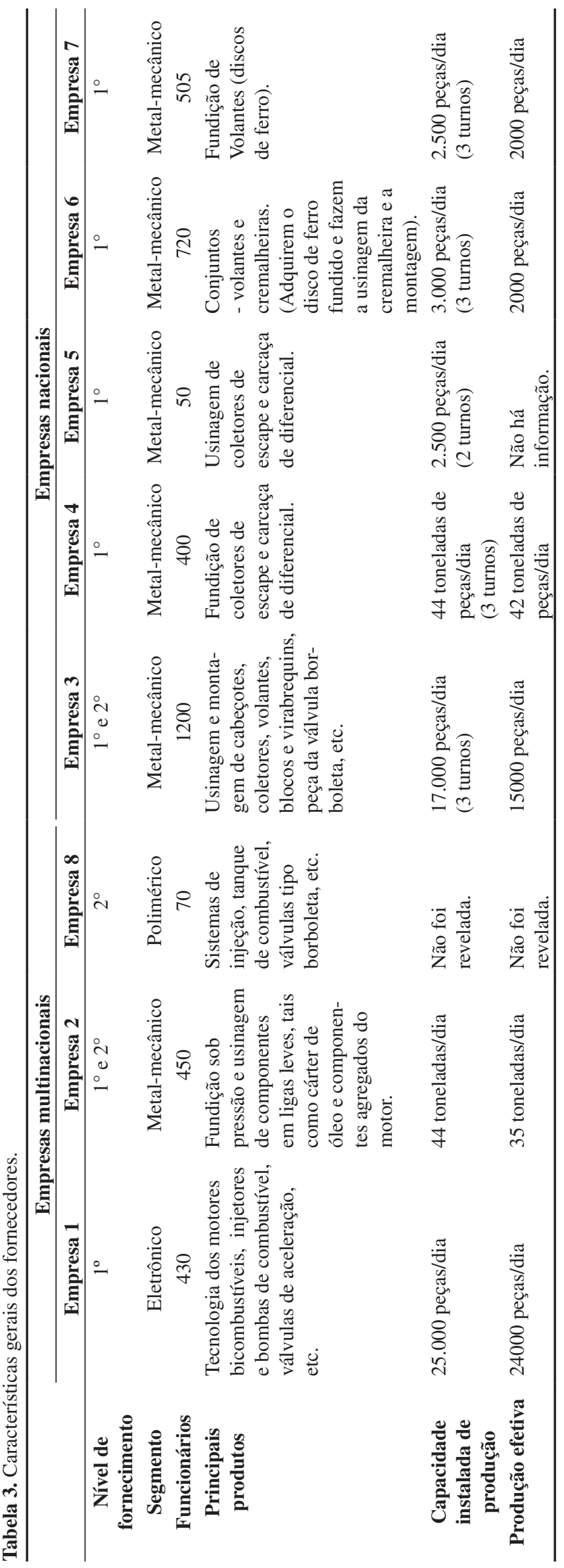




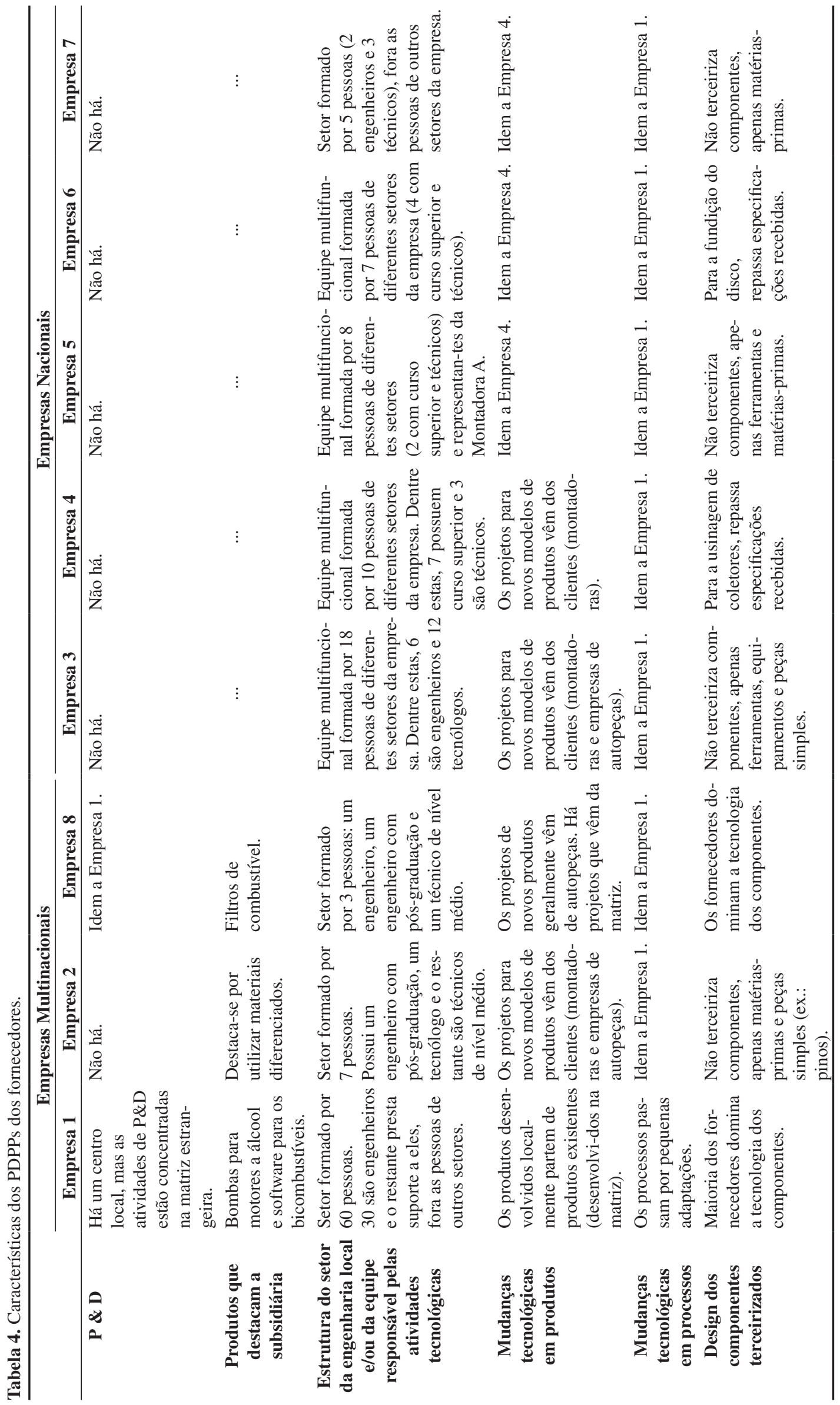




\section{Discussão dos casos}

Conforme indicado na seção sobre o método de pesquisa, os casos buscavam explorar informações relativas à:

a) atividades de Pesquisa e Desenvolvimento que dão embasamento científico e tecnológico para os projetos;

b) capacitação das áreas de projeto das empresas;

c) descentralização e autonomia das subsidiárias brasileiras frente a suas matrizes internacionais; $\mathrm{e}$

d) contexto de inovações nos projetos de produto e processo.

No primeiro aspecto, verifica-se que as montadoras de motores instaladas no Brasil, tanto as entrantes quanto as veteranas (embora em menor grau para as primeiras), concentram as atividades de P\&D em suas matrizes estrangeiras. Com o passar do tempo, as montadoras veteranas foram ampliando as atividades da engenharia local, embora continuem mantendo relações com os centros de pesquisas das matrizes.

No que se refere à capacitação das áreas de projeto, tem-se que as atividades de desenvolvimento de produtos e/ou processos, nas três montadoras estudadas, são conduzidas por equipes multifuncionais, compostas por representantes de diversas áreas - além das pessoas da Engenharia, estas equipes envolvem representante(s) da Produção, Qualidade, Compras, Marketing, entre outras.

As duas montadoras veteranas iniciaram os investimentos em atividades de engenharia de produto no Brasil em períodos diferentes, sendo a Montadora B a pioneira delas, e realizaram desenvolvimentos locais relevantes, especialmente em motores de $1000 \mathrm{cc}$ e de combustíveis flexíveis. Vale ressaltar que a Montadora A foi a pioneira no lançamento de motores 1.0 bicombustíveis.

Ao compararmos o setor voltado às atividades tecnológicas no Brasil de cada uma das veteranas estudadas, podemos observar que, embora na Montadora B haja um número maior de pessoas envolvidas, estas são mais qualificadas na Montadora A - utilizando o número de pessoas que cursaram graduação e pós-graduação como indicador de qualificação. Este fato pode justificar, em parte, o pioneirismo da Montadora A no lançamento de novos modelos de motores.

De modo muito semelhante, as montadoras A e B apresentam autonomia tecnológica crescente para desenvolver localmente novos modelos de motores a partir de outros já existentes e realizar as respectivas mudanças nos processos de produção.

Em seus projetos, nenhuma das montadoras explora tecnologias desenvolvidas por outras empresas para incorporar em seus próprios produtos e processos, como também não exploram (vendem) tecnologias por elas desenvolvidas.
Essas montadoras, além de manterem suas respectivas matrizes como importantes fontes de conhecimentos, conforme já mencionado, também encontram nas cadeias de suprimentos empresas que dominam a tecnologia de componentes importantes para motores. No entanto, as montadoras definem as normas de aprovação de cada componente e dominam a aplicação desses no produto final, ou seja, controlam as interfaces e o conhecimento de como unir os diferentes componentes em um produto com funcionalidade integrada (montagem dos motores).

A Montadora $\mathrm{C}$, vale ressaltar, diferencia-se significativamente das duas primeiras - a matriz da montadora entrante possui diferente estratégia de divisão e localização de atividades de desenvolvimento tecnológico e de projeto de produto com relação à subsidiaria brasileira. Os projetos dos componentes que são passados para os fornecedores, portanto, vêm da matriz. No Brasil há um setor que conta com sete engenheiros responsáveis pelas atividades tecnológicas, que consistem principalmente em adaptar os processos de produção existentes na planta aos novos modelos de motores que são desenvolvidos na matriz.

A partir do ano de 2006, no entanto, a Montadora $\mathrm{C}$ passou a ter como meta criar no Brasil uma "Engenharia de Produto". As pessoas envolvidas em atividades tecnológicas locais, que já eram bastante integradas com a engenharia da matriz, intensificaram os contatos e as trocas de conhecimentos. Estes engenheiros brasileiros estão passando por treinamentos no exterior e pretendem começar a desenvolver novos modelos de motores a partir daqueles que vêm sendo aqui fabricados.

Embora a empresa esteja conduzindo os esforços mencionados acima, a pesquisa de campo revelou que as inovações em produtos, até o momento, continuam sendo realizadas na matriz. Os PDPPs se resumem ao projeto de processos, e mesmo estas atividades tecnológicas são relativamente raras já que os processos não são flexíveis e apenas dois modelos de motores são produzidos.

Ainda no que diz respeito à Montadora $\mathrm{C}$, cabe mencionar que a empresa se diferencia das outras montadoras entrantes. Enquanto a companhia estudada apresenta um mix de motores reduzido, voltado especificamente para exportação à Europa, EUA e Ásia, as outras montadoras apresentam um mix de produtos pequeno (embora mais amplo que "C") e dirigido a determinados segmentos do mercado brasileiro e do Mercosul (ALVES FILHO et al., 2006).

As três montadoras aqui estudadas apresentam diferentes níveis de terceirização na fabricação dos componentes para motores. A Montadora A é a mais terceirizada, a Montadora C (entrante) ocupa uma posição intermediária e a Montadora B pode ser considerada a menos terceirizada das três, embora recentemente tenha 
deixado de produzir internamente uma série de componentes.

Dentre os fornecedores da amostra, apenas a empresa fornecedora de componentes eletrônicos (Empresa 1), dos quais as montadoras são mais dependentes tecnologicamente, desenvolve projetos de produtos e possui um setor de engenharia mais robusto, composto por 60 pessoas. De acordo com informações obtidas na Empresa 1, é relativamente comum encontrar fornecedores seus que desenvolvam produtos e processos (fornecedores de segundo nível das montadoras).

O segmento dos componentes eletrônicos, dada sua complexidade, apresentainterfaces com outros segmentos, recebendo componentes metálicos (ex. Empresa 3) e poliméricos (Empresa 8). Embora a parte metálica da válvula borboleta (componente que regula a passagem de combustível) seja fornecida pela Empresa 3, o módulo de controle eletrônico responsável pela dosagem de combustível no motor é projetado pela Empresa 1. Vale ressaltar que a Empresa 1 cede para a Empresa 3 o projeto do produto e parte do know-how envolvido no respectivo processo de produção.

Por outro lado, as empresas do segmento de componentes metálicos, composto predominantemente por empresas nacionais, apresentam um conjunto inferior de pessoas atuando em atividades tecnológicas (variando entre 5 e 18 pessoas) quando comparado à empresa do segmento eletrônico. Neste segmento, ao menos na amostra estudada, não foram encontrados fornecedores que desenvolvam os projetos dos produtos por eles fabricados, apenas aqueles que se responsabilizam pelo projeto dos processos, em alguns casos com auxílio das montadoras. Verificou-se ainda a existência de uma empresa que não realiza nenhum tipo de atividade tecnológica (Empresa 5).

Diferentemente do que ocorre com outros fornecedores, nas empresas 3, 4, 5 e 6 não ocorre a estruturação de um setor de desenvolvimento, sendo estas atividades desempenhadas por times multifuncionais. Frente a isto, pode-se sugerir que a estruturação física de um departamento seria adequada nestes casos, dado que as empresas recebem o projeto das montadoras, não terceirizam qualquer componente, e os projetos são unicamente de processos (devendo envolver times da produção, manutenção, qualidade, etc.).

Em algumas empresas pequenas do segmento metalmecânico, a Montadora A investiu em equipamentos, conhecimentos tecnológicos (para produtos e processos de produção), auxiliou na certificação de normas de qualidade e enviou engenheiros à planta destas empresas para pessoalmente ajudarem a implementar as melhorias almejadas (ex. Empresas 3 e 4). A Montadora B, por sua vez, também desenvolveu alguns de seus fornecedores, mas foram casos bastante raros, segundo os entrevis- tados (por exemplo, quando a Montadora B terceirizou a usinagem os coletores). Este fato parece estar diretamente relacionado com a estrutura da cadeia e a política de suprimentos adotada por cada montadora: enquanto a Montadora A possui em sua cadeia um número mais elevado de empresas de menor porte e menos capacitadas tecnologicamente, a Montadora B, embora também seja suprida por empresas com tais características, opta por ter um conjunto maior de empresas subsidiárias de multinacionais mais capacitadas.

No caso da Montadora C, esta prática de desenvolvimento de fornecedores não ocorreu. Cabe mencionar que, dentre os 92 fornecedores que a empresa possui, 60 estão localizados no exterior e são empresas de maior porte e capacitadas tecnologicamente. A montadora está nacionalizando a base de fornecedores e acompanha os fornecedores aqui instalados (mesmo aqueles que dominam a tecnologia das peças) quando estes vão iniciar o fornecimento de um componente até então importado.

As cadeias do segmento metal-mecânico apresentam poucos níveis hierárquicos, tendo no segundo nível de suprimentos empresas fornecedoras de produtos menos sofisticados tecnologicamente. Neste segmento, no segundo ou terceiro nível de suprimentos, encontram-se as empresas metalúrgicas e siderúrgicas fornecedoras de matérias-primas. Desse modo, as empresas de primeiro nível tendem a sofrer fortes pressões, estando sujeitas ao poder de barganha das montadoras, no lado da demanda, e ao poder exercido pelas grandes metalúrgicas, no lado do suprimento.

Representando o segmento de componentes poliméricos, tem-se a Empresa 8 da amostra. Esta, apesar do número reduzido de pessoas atuando em atividades de projeto (3 pessoas), atua no segundo nível de suprimento das montadoras apresentando know-how para modificar projeto de produtos de clientes (quando estes permitem), desenvolve produtos para o mercado de reposição, e seus fornecedores (os de terceiro nível das montadoras) são empresas certificadas por normas de qualidade e responsáveis pelos produtos fornecidos (plásticos projetados para serem utilizados na indústria automotiva e eletroeletrônica e resinas termoplásticas).

\section{Conclusões e considerações finais}

Esta pesquisa indica que as montadoras de motores para automóveis precisam coordenar e executar amplo conjunto de atividades relacionadas ao desenvolvimento de produtos e de processos, grande parte delas realizadas por seus fornecedores. Especialmente no que tange ao desenvolvimento de produtos, a ampliação da participação dos fornecedores faz com que as montadoras procurem aperfeiçoar o controle das interfaces e o conhecimento de como unir os diferentes componentes em um 
produto com funcionalidade integrada. Já no que tange ao desenvolvimento de processos, dependendo das capacidades tecnológicas dos fornecedores (atributo definido nos processos de seleção e avaliação de fornecedores), as montadoras despendem maiores ou menores esforços para apoiar os fornecedores em suas atividades.

Esses esforços de coordenação das atividades desenvolvidas nas cadeias de suprimentos e para a ampliação do conhecimento sobre a arquitetura (e aplicação) do produto são despendidos com graus variados de apoio das matrizes das montadoras, dependendo de quão específicos para os mercados regionais são os produtos desenvolvidos e fabricados nas subsidiárias localizadas no Brasil.

Pode-se supor, portanto, que são a articulação e o desenvolvimento de competências internas às montadoras (subsidiárias no Brasil) (tais como conhecimento e desenvolvimento da arquitetura, aplicação do produto integrado, interação com a matriz, coordenação e apoio às atividades realizadas por fornecedores), às empresas matrizes e às empresas fornecedoras que sustentam as vantagens competitivas relacionadas ao desenvolvimento de produtos e processos.

O processo de terceirização que vem sendo implementado pelas montadoras parece não haver reduzido sua capacidade competitiva de inovação, ao contrário, elas puderam:

a) em determinados casos, sobretudo no segmento metal-mecânico (componentes com tecnologia relativamente madura), buscar alternativas que resultaram em reduções no custo de manufatura dos produtos, valendo-se de fornecedores com estrutura de overhead (custos indiretos) menor e responsáveis por ganhos de produtividade nos processos de produção;

b) em outros casos, principalmente no segmento eletrônico (componentes ainda em forte desenvolvimento tecnológico), puderam utilizar a capacidade de fornecedores com know-how especialista no desenvolvimento tecnológico de seus produtos.

Assim, o domínio sobre o conhecimento da integração dos diferentes componentes permite que as montadoras usem eficientemente suas próprias competências e as de suas cadeias de suprimentos para buscar vantagem competitiva no setor. Embora as cadeias de suprimentos das diferentes montadoras de motores apresentem intersecções significativas - muitos fornecedores comuns - e, por isso, não se possa esperar que algum processo de diferenciação (de um conjunto de componentes) possa ser sustentado por longo tempo, uma gestão mais eficaz dos projetos de desenvolvimento de produto e de processos de produção nas cadeias (que pode ser exercida em parte pelas montadoras) pode produzir, pelo menos temporariamente, alguma vantagem competitiva.
Considerando primeiramente as cadeias de suprimentos do grupo das montadoras veteranas, tem-se, portanto, que as empresas apresentam diferentes níveis de terceirização e políticas de suprimentos diferenciadas, e que muitos de seus fornecedores suprem simultaneamente a várias montadoras e possuem diferentes capacidades tecnológicas. Verificou-se que há fornecedores que dominam a tecnologia dos produtos entregues às montadoras (ex. Empresa 1 da amostra) e este parece ser o caso de grande parte dos fornecedores do segmento dos componentes eletrônicos, dos quais as montadoras são mais dependentes em termos de conhecimentos. Existem fornecedores que recebem os projetos de produtos das montadoras e se responsabilizam pelos processos de produção (como são as empresas 2, 6, 7 e 8). Outros fornecedores, além de receberem o design dos produtos, necessitam do apoio das montadoras para desenvolverem e adaptarem os processos de produção (ex. Empresas 3 e 4 da amostra). Há ainda fornecedores que não realizam atividades de desenvolvimento, como é o caso da Empresa 5. Assim, pode-se dizer que, algum domínio das competências de fabricação e de desenvolvimento de processos é necessário para o grupo de empresas nacionais, mas que estas em geral se apóiam em competências (de produto e de processo) das montadoras, que lhes repassam tecnologia para fabricarem dentro dos parâmetros especificados os componentes por elas projetados.

Em síntese, tem-se que as duas montadoras veteranas concentram as atividades de $P \& D$ na matriz e apresentam estratégias competitivas semelhantes. Começaram suas atividades produtivas no início daindústria automobilística brasileira e vêm acumulando, desde então, competências voltadas às necessidades dos consumidores locais e para mercados de países emergentes (embora alguns produtos tenham sido exportados para países desenvolvidos). Elas, portanto, competem nos mesmos segmentos de mercado, com modelos de produtos equivalentes e com alguns fornecedores comuns; desenvolvem produtos a partir de outros desenvolvidos pela matriz; e suas atividades de projeto estão relacionadas a alguns componentes que são produzidos por fornecedores. E estes, geralmente pertencentes ao segmento metal-mecânico, se responsabilizam pelos respectivos projetos dos processos de produção desses componentes, muitas vezes com auxílio das montadoras. Por outro lado, pôde-se verificar que os projetos dos produtos eletrônicos estão sob domínio dos fornecedores, que detêm a tecnologia de seus produtos, e se juntam às montadoras para discutir as inovações demandadas desde o início dos Projetos de Desenvolvimento de Produtos e Processos.

No caso de componentes poliméricos, embora nenhum fornecedor de primeiro nível tenha sido estudado, é possível sugerir que estes possam ocupar um nível intermediário de domínio tecnológico de produtos entre os 
componentes metálicos e eletrônicos. Embora a empresa estudada neste segmento receba dos clientes o design dos produtos, esta possui know-how para alterá-los, além de desenvolver alguns produtos para o mercado de reposição.

A montadora entrante, diferentemente do que foi verificado nas montadoras veteranas, concentra suas atividades de projeto na matriz estrangeira. $\mathrm{O}$ caso estudado mostra que a empresa executa atividades de desenvolvimento de processos no Brasil e está buscando dar início às atividades locais de desenvolvimento de produtos, paralelamente ao processo de busca de fornecedores instalados no Brasil e ampliação do índice de nacionalização dos motores produzidos. Neste contexto, os produtos projetados localmente seriam desenvolvidos a partir dos modelos que aqui já vêm sendo fabricados, e que foram originalmente projetados pela matriz internacional.

No que tange ao projeto de processos nas montadoras, estas atividades permanecem internas às empresas, talvez pela característica relativamente consolidada da tecnologia de produção. Nos fornecedores estudados, as alterações não são de grande monta e, em certos casos, podem ter auxílio das montadoras clientes.

Contudo, o projeto de produtos recebe grande ênfase, dada sua importância para a competitividade das empresas. As montadoras veteranas conseguiram alguns desenvolvimentos locais relevantes, enquanto a entrante busca (de maneira ainda incipiente) realizar desenvolvimentos locais e ampliar o índice de nacionalização de seus produtos. No que se refere aos fornecedores, poucos são os casos em que as empresas possuem capacidade para efetivamente realizar desenvolvimentos - na grande maioria dos casos (sobretudo no segmento metal-mecânico), o projeto é fornecido pela montadora.
Desta forma, os PDPPs realizados pelas montadoras, embora não sejam extraordinariamente efetivos em desenvolver novos (e inovadores) produtos, são particularmente importantes no desenvolvimento dos projetos de peças que irão compor os motores, projetos esses que são repassados aos fornecedores, na maioria das vezes. Neste ponto, PDPPs de montadoras e fornecedores confluem, havendo grande troca de informações entre as diversas partes para a elaboração de um projeto de modo coordenado e que atenda às necessidades estabelecidas pelas montadoras.

Com base nesses aspectos aqui investigados, indicamos alguns possíveis desdobramentos desta pesquisa. Sem pretender esgotar todas as possibilidades, pode-se sugerir:

a) estudar as demais montadoras de motores instaladas no Brasil;

b) estudar outros fornecedores do segmento de componentes microeletrônicos;

c) estudar fornecedores de componentes poliméricos situados no primeiro nível de suprimentos;

d) estudar fornecedores de outros segmentos, como, por exemplo, o de componentes produzidos com materiais químicos;

e) estudar outros fornecedores que pertencem ao segundo nível de suprimentos das montadoras, em cada um dos segmentos (metálico, eletrônico e polimérico);

f) estudar outras empresas nacionais, de forma a verificar se vêm desenvolvendo e produzindo componentes com alguma complexidade tecnológica no segmento de motores para automóveis; e

g) analisar as trajetórias tecnológicas de algumas empresas que foram adquiridas por grupos multinacionais, mas que eram, inicialmente, empresas de capital nacional. 


\title{
Local development projects in the supply chains of newcomers and mature engine manufacturers
}

\begin{abstract}
This paper aims at identifying and comparing projects of product and process development accomplished by two mature and a newcomer automaker considering the context of the supply chains to which they belong. For that, case studies were carried out in three automakers and eight suppliers. Most of the companies studied are responsible for production process projects. In the mature companies, such projects take place almost without any external support (only with a sporadic support of their international headquarters), possibly because the production technology is already consolidated and susceptible only to incremental changes, and because the competences needed for such improvements have already been locally developed. In the newcomer companies, once the production processes have just been set up, the Brazilian branch has been responsible for a few changes implemented since then. Concerning the suppliers, changes in the production process tend to be less complex and, in most cases, these companies can count on the automakers' support. Automakers pay especial attention to product design. The mature companies have already accomplished important local developments, and the newcomers have planned to improve their product development department to start local developments and, mainly, to nationalize their suppliers. Regarding the auto-suppliers, the results indicate that the required levels of technological capability for product development tend to vary according to the technological segments of the automotive supply chains. In the metalworking segment, the suppliers can either receive the product design already specified from the automakers or design projects according to the client demands. In the electronics segment, the suppliers already have the technology and, so they develop components and parts that the automakers simply add to their products. Polymeric suppliers seem to have an intermediate level of products technology knowledge compared to the metalworking and electronics segments.
\end{abstract}

Keywords: Development projects (products and processes). Automotive engines. Supply chains. Automotive industry.

\section{Referências bibliográficas}

ALVAREZ, R. R. O Setor Automotivo no Rio de Janeiro: uma analise na inserção dos fabricantes locais de autopeças na cadeia automotiva. 2004. 932f.. Tese (Doutorado ) - Universidade Federal do Rio de Janeiro.

ALVES FILHO, A. G.; NOGUEIRA, E.; BENTO, P. E.; CERRA, A. L.; MAIA, J. L Operations Strategies of engine assembly pants in Brazil. Artigo submetido. INTERNATIONAL EUROMA CONFERENCE, Proceedings... 2007.

ALVES FILHO, A. G.; CERRA, A. L.; NOGUEIRA, E.; MAIA, J.; MARTINS, M. F.; BONADIO, P. V. G.; BENTO, P. E. G.; RESENDE, R. A.; MARTINS, R. A.; VANALLE, R. M. Estratégias de Produção nas unidades produtoras de motores para automóveis. Relatório Final (Processo CNPq 477515/03-7). 162p. Brasília 2006.

ALVES FILHO, A. G.; NOGUEIRA, E.; SACOMANO NETO, M. BENTO, P. E. G. Estratégias de Produção em cadeias de suprimentos: dois casos na indústria automobilística. ENEGEP - ENCONTRO NACIONAL DE ENGENHARIA DE PRODUÇÃO, Anais... Ouro Preto-MG. 2003.

ANFAVEA - ASSOCIAÇÃO NACIONAL DOS FABRICANTES DE VEÍCULOS AUTOMOTIVOS - Anuário da Indústria Automobilística Brasileira. São Paulo, 2005. Disponível em: $<$ http://www.anfavea.com.br>. Acesso em: 26 jul. 2007.

ASSUMPÇÃO, M. R. P. Reflexão para Gestão Tecnológica em Cadeias de Suprimentos. Gestão \& Produção. v. 10, n. 3, p. 345-362, dez. 2003.
CERRA, A. L. Estratégias Tecnológicas em cadeias de suprimentos da indústria automobilística brasileira: estudos de caso em empresas do segmento de motores de automóveis. 2005. Tese (Doutorado em Engenharia de Produção) Universidade Federal de São Carlos, São Carlos-SP.

CERVO, A; BERVIAN, P. A. Metodologia Científica. São Paulo, Mgraw-Hill, 1983.

COHEN, W. M.; LEVINTHAL, D. A. Absorptive capacity: a new perspective on learning and innovation. Administrative Science Quarterly. Special Issue - Technology, Organizations and Innovation. v. 35, n. 1, p. 128-152, mar. 1990.

CONSONI, F. L. Da Tropicalização ao projeto de veículos: um estudo das competências em desenvolvimento de produtos nas montadoras de automóveis no Brasil. 2004. 269f.. Tese (Doutorado em Política Científica e Tecnológica) - Instituto de Geociências - Universidade Estadual de Campinas, Campinas $-\mathrm{SP}$.

DIAS, A.V. C.; SALERNO, M. S. Construindo competitividade por meio da organização do desenvolvimento de produtos globais: proposições a partir de estudos de caso no setor automotivo brasileiro. In: ENEGEP, 23. 2003. Anais... Ouro Preto, MG, Brasil. CDRom.

FENABRAVE - Federação Nacional da Distribuição de Veículos Automotores. Anuário Fenabrave 2006. Disponível em: <http://www.fenabrave.org.br> Acesso em: 26 jul. 2007. 
FERNANDES, J. M.; ROMEIRO FILHO, E.; ARAKI, L.; REIS, L. P.; FIGUEIREDO, A. C.; VAZ, C.; MARÇAL, F. V.; NOGUEIRA, M. J. S. Cross-functional teams and concurrent engineering: contributions to the development of product design through multidisciplinary integration using CAD systems. Product: Management \& Development. v. 3, n. 1, p. 5-9, aug. 2005.

GOMES, R. O papel das subsidiárias e a internacionalização das atividades tecnológicas pelas empresas transnacionais (ETNs). Revista Gestão \& Produção. v. 10, n.3, p. 267-282, dez. 2003.

HUMPHREY, J.; SALERNO, M. S. Globalization and assemblersupplier relations: Brazil and India. In: HUMPHREY, J.; LECLER, Y.; SALERNO, M. S. (Eds.) Global Strategies and Local Realities. The Auto Industry in Emerging Markets. (in association with GERPISA- Resseau International). Basingstoke, England: Macmillan Press Ltd, 2000.

LAKEMOND, N.; BERGGREN, W.; WEELE, A. Coordinating supplier involvement in product development projects: a differentiated coordination typology. R\&D Management, v.36, n. 4, p. 55-66, 2006.

MAIA, J. L. Alinhamento entre a Estratégia de Operações e a Gestão Estratégica da Logística: Estudos de caso no setor automotivo brasileiro. 230 f.. Dissertação (Mestrado em Engenharia de Produção), DEP/UFSCar, São Carlos, 2006.

MAIA, J. L.; CERRA, A. L.; ALVES FILHO, A. G. Interrelações entre Estratégia de Operações e Gestão da Cadeia de Suprimentos: Estudos de Caso no segmento de motores para automóveis.Gestão \& Produção. v. 12, n. 3, p. 377-391, set.-dez. 2005.

MIGUEL, P. A. C.; ROTONDARO, R. G. An exploratory study on global competitiveness product development in the automotive industry in Brazil. In: INTERNATIONAL EUROMA CONFERENCE, Proceedings... Glasgow, Scotland. p. 505-514, jun. 2006.

MIKKOLA, J. H.; SKJOETT-LARSEN, T. Early Supplier Involvement: implications for new product development outsourcing and buyer-supplier interdependence. Global Journal of Flexible Systems Management. v. 4, n. 4, p. 31-41, 2003.

NEUMANN, C. S. R.; RIBEIRO, J. L. D. Desenvolvimento de fornecedores: um estudo de caso utilizando a troca-rápida de ferramentas. Revista Produção. v. 14, n. 1, p. 44-51, 2004.

PEREIRA, G. M.; GEIGER, A. Complexidade do produto e volume de produção como determinantes da estratégia de desenvolvimento de fornecedores automotivos. Revista Gestão \& Produção. v. 12, n. 2, p. 191-201, maio-ago. 2005.

QUADROS C. R.; QUEIROZ, S. R. R.; CONSONI, F. L.; COSTA, I.; RODRIGUES, R. Globalização e reestruturação da cadeia produtiva na indústria automotiva: qual é o papel do Mercosul? Relatório Final de Pesquisa. Campinas: Convênio IPEADPCT/IG/UNICAMP- FUNCAMP, 2000. Mimeo.

QUIESCENTI, M.; ROMA, P.; BRUCCOLERI, G.; PERRONE, G. A theoretical framework for collaborative engineering in new prouct development in the automobile industry. In: INTERNATIONALEUROMA CONFERENCE, Proceedings... Glasgow, Scotland. p. 1005-1014, jun. 2006.

QUINTELLA, H. L. M. M.; ROCHA, H. M. Avaliação da maturidade do processo de desenvolvimento de veículos automotivos. Gestão \& Produção. v. 13, n. 2, p. 297-310, maio-ago., 2006.

ROZENFELD, H; CALPADO AMARAL, D.; TOLEDO, A. C.; SILVA, S. L.; ALLIPRANDINI, D. H.; SCALICE, R. K. Gestão de Desenvolvimento de Produtos - Uma referência para a melhoria do processo. São Paulo: Editora Saraiva, 2006.

SALERNO, M. S.; MARX, R.; ZILBOVICIUS, M.; GRAZIADIO, T.; MUNIZ, S. T. G.; DIAS, A. V. C.; IVESON, S.; HOTA, M. A.; SOARES, R. Mapeamento da nova configuração da cadeia automotiva brasileira. Pesquisa realizada junto ao BNDES. Escola Politécnica da Universidade de São Paulo, Departamento de Engenharia de Produção. Relatório Final, outubro, 2001.

SILVA, M.; FERREIRA, J. J. A. Uma contribuição ao estudo das empresas inovadoras no Brasil. SIMPOI / FGV-EAESP, XI., Anais... São Paulo, 2006.

SILVA, S. L.; TOLEDO, J. C.; FERARI, F. M. Participação de fornecedores no Desenvolvimento de Produtos: o projeto da nova versão do Fiat Palio. In: CALPADO AMARAL, D. (Org.) Gestão do ciclo de vida dos produtos. Coleção Fábrica do Milênio, V.III, $1^{\circ}$ Edição, p. 71-80, Jaboticabal: Novos Talentos, 2005.

TEIXEIRA, E. C. O desenvolvimento da tecnologia Flex-fuel no Brasil. Instituto DNA Brasil. São Paulo, outubro de 2005.

TOLEDO, J. C.; MARTINS, M. F.; MARTINS, R. A.; SILVA, S. L. Um estudo sobre co-design na indústria automotiva brasileira. In: CALPADO A. D. (Org.) Gestão do ciclo de vida dos produtos. Coleção Fábrica do Milênio, V.III, $1^{\circ}$ Edição, p.55-69, Jaboticabal: Novos Talentos, 2005.

VOLPATO, G. The OEM-FTS Relationship. ACTES DU GERPISA - Réseau International, n. 35, p. 19-44, Paris, décembre 2003.

\title{
Sobre os autores
}

\author{
Aline Lamon Cerra \\ Jonas Lucio Maia

\section{Alceu Gomes Alves Filho} \\ Departamento de Engenharia de Produção, Universidade Federal de São Carlos - UFSCar, \\ Rod. Washington Luís - Km 235, CEP 13565-905, São Carlos, São Paulo, Brasil, \\ e-mails: alinelc@terra.com.br; jonasmaia@ dep.ufscar.br; alceu@power.ufscar.br
}

Agradecimentos: Agradecimentos à FAPESP - Fundação de Amparo à Pesquisa do Estado de São Paulo. 
